Article

\title{
Research on Dynamic Cooperative Replenishment Optimization of Shipbuilding Enterprise Inventory Control under Uncertainty
}

\author{
Ziquan Xiang $\mathbb{D}^{\mathbb{D}}$, Jiaqi Yang, Muhammad Hamza Naseem * $*$ and Wenjie Ge
}

check for updates

Citation: Xiang, Z.; Yang, J.; Naseem, M.H.; Ge, W. Research on Dynamic Cooperative Replenishment Optimization of Shipbuilding Enterprise Inventory Control under Uncertainty. Sustainability 2022, 14 , 2113. https://doi.org/10.3390/ su14042113

Academic Editors: Tingsong Wang, Shuaian (Hans) Wang, Jianfeng Zheng and Yadong Wang

Received: 15 January 2022

Accepted: 10 February 2022

Published: 12 February 2022

Publisher's Note: MDPI stays neutral with regard to jurisdictional claims in published maps and institutional affiliations.

Copyright: (c) 2022 by the authors. Licensee MDPI, Basel, Switzerland. This article is an open access article distributed under the terms and conditions of the Creative Commons Attribution (CC BY) license (https:/ / creativecommons.org/licenses/by/ $4.0 /)$.
School of Transportation and Logistics Engineering, Wuhan University of Technology, Wuhan 430063, China; Xiangziquan@whut.edu.cn (Z.X.); styjq@whut.edu.cn (J.Y.); gewenjie@whut.edu.cn (W.G.)

* Correspondence: muhammadhamza@whut.edu.cn

\begin{abstract}
Aiming at the problem of high inventory control costs of shipbuilding enterprises under uncertain conditions, this paper constructs and optimizes a dynamic collaborative replenishment model of shipbuilding enterprises inventory control. This model adopts integrated supply chain management theory and collaborative theory to analyze the inventory control principle in shipbuilding enterprises, and its goal is to minimize the cost and maximize the service level. The dynamic replenishment strategy from two types of suppliers is given by using mathematical knowledge, such as optimization theory, probability theory, and mathematical statistics to solve the model. Finally, shipbuilding enterprises take paint inventory control as an example to test and verify the validity and correctness of the model by using numerical simulation and sensitivity analysis. The results show that the dynamic collaborative replenishment model of shipbuilding enterprises inventory control can make full use of the advantages of two types of suppliers. Additionally, it cannot only quickly respond to demand changes, but can also maintain low operating costs. Therefore, the dynamic collaborative replenishment model could effectively solve the problem of high inventory control costs of shipbuilding enterprises under uncertain conditions and has great application value and practical significance.
\end{abstract}

Keywords: uncertain conditions; shipbuilding enterprises; inventory control; dynamic coordination; supply chain management

\section{Introduction}

Inventory refers to the sum of various items and resources stored in an enterprise organization and is an unavoidable aspect of the operation and management of the production system. In general, people set up inventories to prevent shortages, just like water stored in reservoirs. In addition, they also have the role of maintaining the continuity of the production process, sharing the ordering costs, and quickly satisfying the users' ordering needs. In enterprise production, although inventory exists for various economic considerations, inventory is also a result of helplessness. Because people cannot predict future changes in demand, they cannot use inventory to cope with changes in the outside world. Inventory management under the supply chain management model is to inventory raw materials, supporting equipment, and products under demand uncertainty to ensure the continuity, stability, and rhythm of production and operation; share ordering costs; and monitor supply, the quality of goods, and the management activities carried out to meet the production requirements in a timely and rapid manner. For shipbuilding companies, in inventory management costs, the cost of materials required generally exceeds $60 \%$ of the total production cost. Logistics are mostly based on production. However, shipbuilding companies have complicated production processes and many uncertain factors. They are difficult for the purchasing department to accurately grasp when purchasing materials, and for the inventory department, they are not easy to manage when controlling the inventory. 
Therefore, the inventory of shipbuilding companies has always been high. At present, there are two main problems in the inventory management of shipbuilding enterprises. One is the problem of material warehouse utilization. The limited space of the material warehouse and the long storage time of materials have led to a serious backlog of materials, making the utilization rate of the warehouse not high, which makes it difficult to meet the needs of smooth production and future expansion of production. The second is the storage cost of the inventory department. The backlog of materials occupies a large amount of working capital: not only will the storage cost of shipbuilding enterprises increase, but also the ability to resist risks and adapt to the market, and the operating efficiency of the enterprise will also decrease. If the shipbuilding company can minimize inventory and turn over materials (zero inventory) as quickly as possible, then management costs can be greatly reduced, working capital occupied will also be greatly reduced, and profits will be greatly increased. Therefore, shipbuilding companies attach great importance to material inventory management, shortening the material turnover time, and increasing the utilization rate of working capital, which is of great significance.

In the 1970s, the German expert Harken conceived of and established a collaborative discipline. He attributed this theory to a phenomenon. This theory is mainly used in various parts of the entire organization for the next step, in the new space-time dimension and spatial structure. A stable structure of a certain state is formed on the above; this change is to reduce the internal conflicts of the system, better align the pace, promote higher efficiency, and make the entire organization stable and orderly. Synergy theory is based on the perspective of overall evolution to study the law of synergy between some systems in the whole under the influence of external factors, such as environment, information, etc., through the internal interaction of the whole [1]. The formation elements of the entire organization are mainly through a certain interaction relationship and the collision and exchange of various factors between the organization in a certain surrounding environment, which evolve into a new structure and order, and a stable state of the overall performance of the organization. The collaborative theory is based on multiple developments of various disciplines and disciplines that promote each other, penetrate each discipline, and have a wide range of applications. The theory shows that the higher the degree of collaboration among the various parts of the entire organization, the more stable the state of the entire organization. Integrated supply chain management is the integration of independent member supply chains into a collaborative system, thereby improving the overall efficiency of the supply chain and thus gaining competitiveness. The starting point of integrated supply chain management is to focus on the optimal total cost of the entire supply chain rather than the optimal cost of a single link. In the case of non-cooperation, each member of the chain conducts a game based on their interests, and the result of the game often leads to the sub-optimization of the overall benefits of the supply chain. The integrated management of the supply chain can only achieve good synergy, and the better the performance of the entire shipbuilding supply chain, the more efficient the synergy effect can be. On the contrary, if the various organizations within the supply chain restrict each other, there is friction or conflict, or the links are not smoothly connected, it will inevitably cause unnecessary waste of the internal organization of the entire supply chain, causing the entire supply chain to fall into a disordered state. Mahuya Deb et al. [2] built a neuro-fuzzy system (NFS) for an inventory control decision support system to control production and supply. Wenfang Yu [3] and others proposed a more systematic and improved supply chain inventory optimization model based on the ant colony algorithm and the basic idea of a fuzzy model for the problem of high inventory in supply chain management. Ajoy Kumar Maiti [4], aiming at the inventory cost problem of a supply chain composed of a single supplier and multiple retailers, established a dual-object supplier management fuzzy inventory. Javad Sadeghi et al. [5] studied the fuzzy requirement to be expressed by the trapezoidal fuzzy number (TFN) and used the geometric center of gravity method to defuzzify. Chandra K. Jaggi et al. [6] proposed an inventory management model algorithm that uses fuzzy logic to build an unknown resource demand model. Mor Rahul S. et al. [7] 
found through research that in the field of production management, inventory control and response are just-in-time management. The basic idea is to "provide the right product in the right quantity at the right time." That is the pursuit of minimum inventory. The basic idea is planning and production control, so the just-in-time production model is also called "lean production." P.S. Borle et al. [8] found that companies need to organize professional training for employees and take measures to improve their enthusiasm. All employees must be encouraged to participate in improving the use of collective wisdom and jointly promote the punctual spirit of lean production. They always pay attention to their performance and work together to improve performance and inventory status. Mateusz Budynek et al. [9] combined the survey results and found that in the establishment of the JIT Kanban management system, everyone has clear responsibilities and positions, as well as their real-time situation and performance. Constantly constructing the exceptionhandling process, everyone can work more efficiently and contribute to the collective performance. Kanban management can enhance employees' enthusiasm for work and improve inventory control and management. Gérard P. [10] believes that enterprises should establish a reasonable information-sharing system to achieve a win-win situation through real-time sharing of market information. This is important to avoid a waste of resources and improve the efficiency of enterprise inventory control management. Under the VMI model, customers and suppliers can establish a common information database and negotiate with each other to bring economic benefits to the entire enterprise. Jeong Eun Lee [11] proposed that the premise of establishing a dialogue platform between enterprises is to establish an effective communication mechanism to ensure that relevant parties can obtain the correct information promptly. Raymond Kelly [12] believes that a two-way information exchange platform can be established to improve the level of inventory control management. In this way, the consistency and effectiveness of the business pace between suppliers can be effectively improved. Relevant departments or companies can browse the information released by other companies at any time and incorporate these data into the reference range of the plan. In this process, as long as a supplier cannot meet the supply, it is impossible to meet the ever-changing production needs. In summary, many scholars have studied inventory control problems under certain and uncertain conditions [13-15], but the inventory management of shipbuilding enterprises has its unique characteristics. Based on this, this article integrates the supply chain of shipbuilding enterprises to analyze the inventory control factors of shipbuilding enterprises under uncertain conditions based on integrated management and collaboration theory, construct a dynamic collaborative replenishment model for shipbuilding enterprises' inventory control, and optimize the solution. The innovations and main contributions of this article are as follows:

(1) Analyze the principle of inventory control of shipbuilding enterprises based on the synergy theory and the idea of supply chain integration. In the current literature, analysis of the inventory control principle of shipbuilding enterprises by using the synergy theory and the idea of supply chain integration cannot be found. This paper applies the synergy theory and the idea of supply chain integration to a new field: inventory control optimization of shipbuilding enterprises for the first time.

(2) Construct a dynamic collaborative replenishment model for shipbuilding enterprises' inventory control. Shipbuilding companies face many suppliers. Generally, suppliers can be divided into two categories: The first category is strategic suppliers, which have large order quantities, low prices for individual products, and a slightly longer lead time. This type of replenishment is called lean replenishment. The second category is flexible suppliers, whose ordering quantity is small, price of a single product is high, and lead time is short. This type of replenishment is called flexible replenishment. This model makes full use of the advantages of the two types of suppliers, can quickly respond to changes in demand, and also maintains a low operating cost, and it is used in the paint inventory management of shipbuilding companies.

(3) Enriches research on inventory control and management of shipbuilding enterprises under uncertain conditions. At present, inventory control research is mainly used in the 
automobile manufacturing industry and other companies, while the inventory control of shipbuilding companies is relatively small, especially the research on inventory control under uncertain conditions.

The structure of this article is as follows. Section 2 gives a literature review of this article. Section 3 introduces, in detail, how to establish and solve the dynamic collaborative replenishment optimization model of shipbuilding enterprise inventory control. Section 4 takes the paint inventory control of a shipbuilding company in Shanghai, China as an example and conducts sensitivity analysis to verify the effectiveness of this model. Section 5 gives the main conclusions of this paper and the next research direction.

\section{Literature Review}

\subsection{Characteristics of Inventory Management in Shipbuilding Enterprises}

(1) Shipbuilding belongs to order-based production. Shipbuilding companies start production after receiving orders from shipowners and signing production contracts. Inventory demand is not a forecast of market demand but is determined following the material demand plan coordinated with the production schedule. However, this does not mean that inventory management has reduced its role in the production and operation of shipbuilding enterprises. On the contrary, the requirements for materials and equipment in place at each stage and each node are more stringent to ensure the normal implementation of the planned production process. Therefore, the stronger the connection between planning and design, the stricter the requirements for inventory management. The problems often encountered in the shipbuilding supply chain are unbalanced workshop demand, a wide variety of products, complex batch combinations, frequent order changes by customers, urgent delivery dates, large random fluctuations in system capacity, and bottlenecks that shift with orders and personnel work efficiency fluctuations. The system operation process is more difficult to accurately control, and so on. Current operation planning and control strategies (such as just-in-time JIT) are most suitable for large-volume deterministic production models, but it is difficult for shipbuilding enterprises' inventory control systems to work because of many uncertainties. How to rationally organize the entire supply chain system instead of just emphasizing the responsiveness of a single node and improve the operational capabilities of the entire supply chain through system optimization methods to reduce the cost of inventory control of shipbuilding enterprises is the key to solving the problem.

(2) The types and specifications of inventory materials of shipbuilding enterprises are complicated. The shipbuilding enterprise is a typical "convergence type" production enterprise, with a variety of materials and equipment input and only one product output. To complete the orderly integration of these many materials is a very huge project in itself. A ship is a large-scale integrated water structure that integrates living, working, entertainment, and other requirements, especially in the cases of large cruise ships or warships. The types and quantities of materials and materials required are unmatched by other manufacturing industries. The required materials and equipment are more diverse, with different values, and the difficulty of purchasing is even more different. Therefore, it is necessary to adopt different inventory management modes for various materials and equipment to better improve its inventory management level.

(3) Zero finished product inventory mode. In the general supply chain structure, the downstream of manufacturers are agents and distributors and then consumers and users. In the shipbuilding industry, the shipbuilding enterprise directly faces the shipowner, and the completed ship is delivered directly to the shipowner, so there is no need to set up the finished product inventory function separately.

\subsection{Research on the Inventory Management Strategy of Shipbuilding Enterprises}

In the traditional supply chain, each link is an independent and closed unit. Considering its interests, it maintains a certain amount of inventory, and to prevent risks, it will increase a certain amount of inventory, which will cause the expansion of demand 
in the supply chain and form a backlog. Shipbuilding companies face many suppliers. Generally, suppliers can be divided into two categories. The first category is strategic suppliers, which have large order quantities, low prices for individual products, and a slightly longer lead time. This type of replenishment is called lean replenishment. The second category is flexible suppliers, whose ordering quantity is small, price of a single product is high, and lead time is short. This type of replenishment is called flexible replenishment. In the supply chain management environment, all partners should strengthen communication, sign medium and long-term cooperation agreements, establish strategic partnerships, make full use of the resource advantages of enterprises at each node of the supply chain, and reduce the impact of commodity price fluctuations. The practice has proved that the alliance relationship established between shipbuilding enterprises and iron and steel companies, such as Anshan Iron and Steel and Baosteel, have brought huge benefits to both parties. Due to the intensified global competition and the extremely uncertain inventory management of shipbuilding enterprises, to quickly respond to changes in workshop demand, it is necessary to select a group of suppliers with flexible production capabilities. Based on the principle of self-interest, shipbuilding enterprises consider the maximum service level and the minimum total cost of replenishment goals and choose a strategic model of joint replenishment from strategic suppliers and flexible suppliers. In the inventory management of shipbuilding enterprises under uncertain conditions, the selection of the probability distribution of the next cycle demand is very important. For materials that consume a lot of money, a normal distribution is more appropriate. For materials with relatively small consumption, Poisson distribution or Laplace distribution is more appropriate [16-18].

To cope with the changes in the market demand environment of shipbuilding enterprises, aiming at the uncertainty of inventory control of shipbuilding enterprises, the probability distribution of demand in the next cycle is fitted by an appropriate probability distribution function, which has more practical significance. The joint replenishment strategy of strategic suppliers and the flexible suppliers is adopted to replenish goods, making full use of the respective advantages of strategic suppliers and flexible suppliers. They play a game with each other in the shipbuilding supply chain system, and there is a relationship of competition and cooperation. The advantage of strategic suppliers is to pursue flat production to reduce production costs; the primary consideration of flexible suppliers is to quickly respond to the uncertain demand of the market. The joint replenishment of the two types of suppliers can better reduce the total inventory cost, thus showing the competitive advantage of their combination.

\section{Shipbuilding Enterprise Inventory Control Dynamic Collaborative Replenishment Optimization Model}

3.1. The Principle of the Dynamic Collaborative Replenishment Model of Shipbuilding Enterprises Inventory Control

Shipbuilding companies choose more suppliers, which can generally be divided into two types: strategic suppliers and flexible suppliers. Strategic suppliers are suitable for mass production, with high production setup costs, low single product prices, and long order lead times; flexible suppliers are suitable for flexible small batch production, with low production setup costs, high prices for individual products, and relatively long order lead times. Therefore, consider a two-level supply chain consisting of a strategic supplier, a flexible supplier, and a shipbuilding company. The dynamic replenishment structure is shown in Figure 1. 


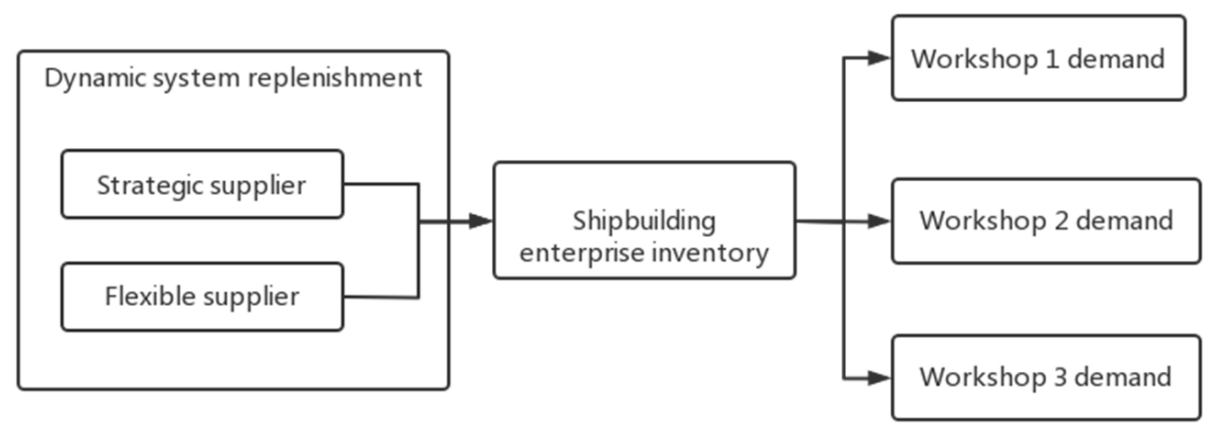

Figure 1. Structure diagram of shipbuilding enterprise inventory control dynamic collaborative replenishment.

The dynamic collaborative replenishment process of shipbuilding enterprises consists of four departments that combine the demand forecast of each workshop in the future cycle of shipbuilding enterprises, dynamic inventory management, and real-time decisionmaking. The principle of dynamic collaborative replenishment is shown in Figure 2. The principle of dynamic collaborative replenishment is as follows: the demand planning department forecasts the demand information of the next cycle; the inventory management department is responsible for managing the inventory of various materials and transmitting the real-time inventory information to the decision-making department; the decisionmaking department receives the demand information of each workshop transmitted by the demand planning department and the real-time inventory information transmitted by the inventory control department and issues replenishment instructions to strategic suppliers and flexible suppliers according to the formulated replenishment strategies and rules; strategic suppliers and flexible suppliers replenish goods according to the instructions of decision-making departments and transport them to shipbuilding enterprises on time.

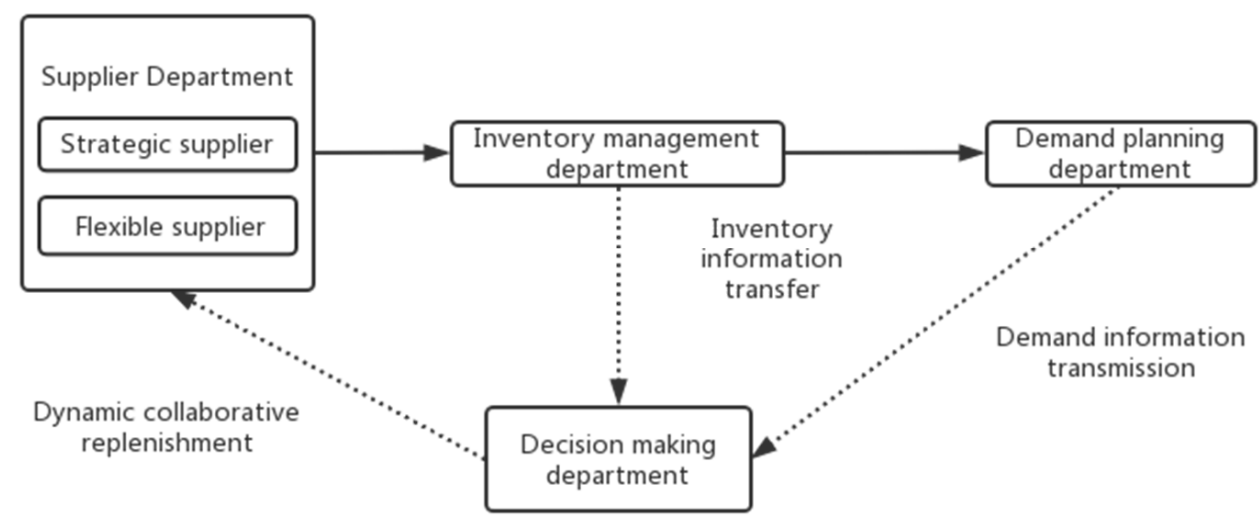

Figure 2. Schematic diagram of dynamic collaborative replenishment of shipbuilding enterprise inventory control.

\subsection{Model Assumptions and Symbol Definitions}

Make the following assumptions:

Consider the single product demand of a certain raw material or parts of the shipbuilding enterprise, which are random variables, and the market demand obeys a certain probability distribution after fitting. In order to explain the application of this model, it is assumed that it obeys normal distribution.

The replenishment lead time of strategic suppliers and flexible suppliers is greater than zero, and the order lead time of strategic suppliers is greater than that of flexible suppliers. 
The inventory of shipbuilding enterprises shall be inspected periodically, and the replenishment method for each periodical inspection shall be to make up to the target inventory level.

Allowing out-of-stocks will result in out-of-stock costs. Some products that are out of stock will have their replenishment postponed, and excess demand will be placed in the next cycle.

Shipbuilding enterprises share information with two suppliers, and the delivery capacity of strategic suppliers and flexible suppliers in each cycle is unlimited and can be delivered on time.

Each time a strategic supplier and a flexible supplier order, regardless of the order quantity, they will each incur a fixed order cost.

Make the following symbol definitions:

$$
S_{i}=\left\{\begin{array}{l}
\text { Strategic supplier } i=1 \\
\text { Flexible supplier } i=2
\end{array}\right.
$$

$T$ : Time length of regular inventory inspection;

$k$ : Number of $k$-th plans; the maximum number of $k$-th plans is the $N$-th, and the length of each period is $T$, that is, $k \in\{1,2, \cdots, N\}$;

$t$ : Time $t$;

$D_{t}$ : The total demand of each workshop of a shipbuilding enterprise is a random variable that obeys a normal distribution pattern and is independent and identically distributed. The mean is $\mu_{t}$ and the variance is $\sigma_{t}^{2}$, that is $D_{t} \sim N\left(\mu_{t}, \sigma_{t}\right)$;

$I W_{t}$ : Inventory of a certain raw material or part of the shipbuilding company at the beginning of time $t$;

$I W_{t}{ }^{\prime}$ : Inventory of a certain raw material or part of the shipbuilding company at the end of the time $t$;

$$
O R_{i}=\left\{\begin{array}{lr}
\text { Order lead time of strategic suppliers } & i=1 ; \\
\text { Flexible supplier lead time } & i=2 .
\end{array}\right.
$$

$L$ : Shipbuilding company's joint order lead time from two suppliers;

$e_{i}$ : Fixed cost for each order from the supplier, and $e_{1}>e_{2}$;

$b_{i}$ : Unit product cost per order from supplier $i$, and $b_{1}<b_{2}$;

$H D$ : Inventory storage cost of a unit product generated in a unit time;

$S C$ : Lost cost per unit product shortage in unit time;

$S L$ : Service level, the probability that the demand during the replenishment cycle is not higher than the target inventory level; there is $P\left(d_{T+L} \leq U\right) \geq S L$;

$$
X_{i, t}=\left\{\begin{array}{ll}
1 & Q_{i, t}>0 \\
0 & Q_{i, t}=0
\end{array} \quad i \in\{1,2\}, t \in\{1,2, \cdots, N\}\right.
$$

Decision variables:

$U$ : Target inventory level;

$Q_{i, t}$ : Quantity of a certain raw material or component replenished from supplier $i$ during plan $t$.

\subsection{Model Establishment}

In this paper, there are two objective functions: one is the total cost of the shipbuilding company's purchase of materials; the other is the service level of the shipbuilding company that will not likely be out-of-stock during the replenishment period.

The demand $D_{t}$ of the shipbuilding workshop is independent and identically distributed, assuming that they all obey the normal distribution, and the total expected demand is a certain number during the planning period. This article allows backorders. When the total cost of the shipbuilding enterprise is the smallest, its total profit will be 
maximized at the same time. Therefore, the first objective function is to minimize the total cost of a certain raw material or parts purchased by the shipbuilding company.

Service level refers to the probability that a shipbuilding company will not be out of stock during the replenishment period. It is also called the order fulfillment rate. This article fixes its value range in the range $[50 \%, 100 \%]$. The service level comes from the significance level $\alpha$ of mathematical statistics. We denote the service level as SL. Then, the probability of being out-of-stock is $1-S L$; here is the statistical significance level $\alpha$. The probability corresponding to the significance level $\alpha$ is called the critical value, which can be represented by $Z_{\alpha}$. Therefore, the service level $S L$ is taken as the second objective function.

Based on the above assumptions and symbol definitions, the following dynamic collaborative replenishment optimization model can be established:

$$
\begin{gathered}
\operatorname{Min} \lambda_{1}=\sum_{i=1}^{2} \sum_{t=1}^{N}\left(e_{i} * X_{i, t}+b_{i} * Q_{i, t}+J_{t}\right) \quad t \in\{1,2, \cdots, N\} \\
\operatorname{Max} \lambda_{2}=S L
\end{gathered}
$$

Constraints:

$$
\begin{gathered}
I W_{t}^{\prime}=I W_{t}+Q_{1, t}-D_{t} \quad t=(k-1) * T+O R_{1} \\
I W_{t}^{\prime}=I W_{t}+Q_{2, t}-D_{t} \quad t=(k-1) * T+O R_{2} \\
I W_{t}^{\prime}=I W_{t}-D_{t} \quad t \neq(k-1) * T+O R_{1} \quad \text { and } \quad t \neq(k-1) * T+O R_{2} \\
I W_{t-1}^{\prime}=I W_{t} \quad t \in\{1,2, \cdots, N\} \\
Q_{1, t}+Q_{2, t}=U-I W_{t} \quad t \in\{1,2, \cdots, N\} \\
P\left(d_{T+L} \leq U\right) \geq S L \\
X_{i, t} \in\{0,1\} \quad Q_{1, t}, Q_{2, t} \in\{0\} \cup N^{+} \quad t \in\{1,2, \cdots, N\}
\end{gathered}
$$

Among them: Equation (1) represents the total cost of the shipbuilding enterprise, which includes three costs: the fixed order fee cost of replenishing the goods from the supplier; the cost of a certain raw materials or spare parts replenished from the supplier; and inventory management and shortage of the cost of loss of goods. Equation (2) represents the service level of the shipbuilding enterprise without the probability of being out-of-stock during the replenishment period. Equation (3) represents the change in the inventory status of the materials ordered by the strategic supplier at a certain moment. Equation (4) represents the change in the inventory status of the materials ordered by the flexible supplier at a certain time. Equation (5) represents the inventory status change when no materials ordered by the supplier arrive at a certain moment. Equation (6) indicates that the inventory of the shipbuilding company at the end of $\mathrm{t}-1$ is equal to the inventory at the beginning of $t$. Equation (7) indicates that the replenishment volume in period $t$ is equal to the sum of the dynamic collaborative replenishment volume from strategic suppliers and flexible suppliers. Equation (8) indicates that the service level is greater than or equal to $S L$. Equation (9) represents the value range of decision variables.

In the period $t, \quad \lambda_{1}$ represents the objective function in subfunction, and $J_{t}$ represents the sum of the management inventory cost and the out-of-stock cost. The specific expression is as follows:

$$
J_{t}=\left\{\begin{array}{lll}
H D * \frac{I W_{t}^{\prime}+I W_{t+1}^{\prime}}{2}, & I W_{t}^{\prime}>0, & I W_{t+1}^{\prime}>0 \\
S C *\left(-\frac{I W_{t}^{\prime}}{2}\right)+H D * \frac{I W_{t+1}^{\prime}}{2}, & I W_{t}^{\prime} \leq 0, & I W_{t+1}^{\prime} \geq 0 \\
S C *\left(-\frac{I W_{t}^{\prime}}{2}\right)+H D * \frac{I W_{t+1}^{\prime}}{2}, & I W_{t}^{\prime}>0, & I W_{t+1}^{\prime}<0 \\
S C *\left(-\frac{I W_{t}^{\prime}+I W_{t+1}^{\prime}}{2}\right), & I W_{t}^{\prime} \leq 0, & I W_{t+1}^{\prime} \leq 0
\end{array}\right.
$$




\subsection{Model Solving}

As the first step to solving the dynamic collaborative replenishment optimization model, the bounded objective method is used to transform the dual-objective decisionmaking model into a single-objective decision-making model. The bounded objective method is very efficient in multi-objective optimization decision-making problems. It captures one of the main goals and allows other goals to meet certain constraints in order to obtain more information about the decision-making problem and conduct sensitivity analysis [19]. Regarding the second goal (i.e., maximizing the service level) as a constraint, we also considered the upper and lower limits of the service level:

$$
S L \in[50 \%, 100 \%]
$$

The order lead times of strategic suppliers and flexible suppliers are $O R_{1}$ and $O R_{2}$ respectively, and $O R_{1}>O R_{2}$. Therefore, the order lead time for dynamic collaborative replenishment from these two suppliers should meet these conditions:

$$
O R_{1} \geq L \geq O R_{2}
$$

In the period $t$, the random demand of a certain raw material or component of the shipbuilding enterprise is $D_{t}$, the mean is $\mu$, the standard deviation is $\sigma$, the periodic inventory check cycle is $T$, and the joint order lead time is L. According to Formula (11), the expression of the target inventory level $U$ can be obtained:

$$
U=\mu *(T+L)+Z * \sigma *(T+L)^{\frac{1}{2}}
$$

Based on Equations (11) and (12), we can obtain

$$
U \in\left[\mu *\left(T+O R_{2}\right)+Z * \sigma *\left(T+O R_{2}\right)^{\frac{1}{2}}, \mu *\left(T+O R_{1}\right)+Z * \sigma *\left(T+O R_{1}\right)^{\frac{1}{2}}\right]
$$

The initial value $U_{1}$ of the target inventory level $U$ can be set as:

$$
U_{1}=\mu *\left(T+O R_{2}\right)+Z * \sigma *\left(T+O R_{2}\right)^{1 / 2}
$$

Let $\omega$ be the adjustment parameter, and its value range is as follows:

$$
\omega \in\left[0, \mu *\left(O R_{1}-O R_{2}\right)+Z * \sigma *\left(T+O R_{1}\right)^{\frac{1}{2}}-Z * \sigma *\left(T+O R_{2}\right)^{\frac{1}{2}}\right]
$$

The algorithmic steps to determine the target inventory level are as follows:

Step 1: Set the initial value $U_{1}$ of the target inventory level and the stock-out loss parameter $S L$. If the service level during the planning period cannot meet the established constraints, the out-of-stock loss parameter $S L$ will be increased, and then the proportion of orders from the two suppliers will be adjusted so that the service level meets the established constraints. Calculate and write down the minimum cost under the $U_{1}$ value.

Step 2: Adjust the value of the parameter $\omega: U=U_{1}+\omega$. Go to step 1 to calculate.

Step 3: Select the $U$ value corresponding to the minimum cost based on the minimum cost under all $U$ values.

Dynamic coordinated replenishment strategy: At the beginning of time $t$, the shipbuilding company determines the dynamic coordinated order quantity to be issued to two suppliers at the beginning of $t$ based on the current inventory and forecasted consumption in the next cycle. The replenishment strategy is determined with the goal of minimizing the total cost of the shipbuilding enterprise in the next cycle.

$$
\operatorname{Min} \lambda=\left(e_{1} * X_{1, t}+e_{2} * X_{2, t}+b_{1} * Q_{1, t}+b_{2} * Q_{2, t}\right)+J\left(O R_{2}\right)+J\left(O R_{1}-O R_{2}\right)+J\left(T-O R_{1}\right)
$$

Constraints: Equation (2) to Equation (9). 
In the objective function, $J\left(O R_{2}\right)$ represents the cost of inventory storage and outof-stock from $t$ to $t+O R_{2} ; J\left(O R_{1}-O R_{2}\right)$ represents the cost of inventory storage and out-of-stock from $t+O R_{2} ; J\left(O R_{2}\right)$ represents the inventory storage and out-of-stock costs from $t+O R_{1}$ to $t+\mathrm{T}$.

In each cycle, the number of ordering instructions issued to strategic suppliers and flexible suppliers is fixed, which can be regarded as a resource allocation problem. There are two ways to solve this model. One is to use the recurrence relation of dynamic programming to solve the problem. The second is to use the discrete gray wolf algorithm to solve the problem. The specific solution method and steps are in the literature [20]. In each cycle, MATLAB software programming is used to solve this model. After determining the initial inventory, ordering product cost, unit product cost, service level, etc. of a certain raw material or parts of the shipbuilding company, the model can be solved to obtain the best replenishment instruction for each cycle. After obtaining the best replenishment instructions for each cycle, the relevant values are substituted into Equation (1) to obtain the total cost of the shipbuilding enterprise during the planning period.

\section{Case Analysis}

\subsection{Problem Description}

Take the purchase of paint by a shipbuilding company in Shanghai as an example. The shipbuilding company has become one of the most large-scale, modern, professional, and influential shipbuilding companies in the industry. After investigation, it is found that the construction of paint has strong timeliness. The interval between the overcoating of paint and the practical validity period after the paint bucket is opened is very short. The paint construction must be completed within the specified time. The construction pace of the shipyard requires that each process must be completed quickly in accordance with the specified time, and the painting construction must be carried out within the specified time; otherwise, it will have a great impact on the on-time production of the shipbuilding enterprise. Moreover, painting construction is affected by weather changes, so the demand for paint in each cycle is uncertain and a random number. The shipbuilding company's paint materials have been stored for a long time, and each time the material purchases are made in large batches, the material purchases are inconsistent with the needs of the production department, resulting in a large backlog of inventory. From 1 January 2019 to 31 October 2019, the storage volume was 36,000 barrels (3600 barrels ordered per month), and the cumulative volume out of storage was 24,323 barrels. After calculation, the average is about 80 barrels per day.

Assuming that the daily demand for paint follows a normal distribution $D_{t} \sim$ $N(80,40)$, the annual shipbuilding company's total planning period is $t=360$ days, and the periodic inspection length is $T=9$ days. The order lead time of the first type of supplier, that is, the strategic supplier, is $O R_{1}=4$ days, and the order lead time of the second type of supplier, that is, the flexible supplier, is $O R_{2}=2$ days. For each ordering cost $e_{1}=\$ 1000, e_{2}=\$ 100$, unit purchase cost $b_{1}=\$ 11, b_{2}=\$ 14$, unit out-of-stock cost $S C=\$ 2.5$, unit storage cost $\mathrm{HD}=\$ 0.8$, the service level is set to $95 \%$. Take $t=1$ a day as the time unit to produce the daily demand for paint in the MATLAB software. The daily demand should be greater than or equal to zero. If there are data less than zero in the simulation data, they should be corrected to 80 .

\subsection{Calculation Results}

If the original monthly ordering method of the shipbuilding enterprise is adopted, the monthly fixed order quantity will be determined at the beginning of the year, the monthly order will be 3600 barrels per month, and the order will be completed at one time. Assuming all orders are from strategic suppliers, after calculation, the total cost is as follows:

Fixed fee per order: $1000 \times 12=12,000$

Inventory storage fee: $\frac{3600}{2} \times 0.8 \times 360=518,400$ 
Order cost fee: $3600 \times 12 \times 11=475,200$

Total cost: $12,000+518,400+475,200=1,005,600$

After $t=1$ a day as the time unit, the daily simulated demand for paint is generated in the MATLAB software and then calculated using the model and method of this article. The relevant parameters are set according to the above, the inventory cost at the beginning of the year is set to $I W_{1}=U=1099$, and the calculated simulation result is shown in Figure 3. The comparison of the replenishment costs of the four methods is shown in Table 1. It can be seen from Table 1 that the monthly replenishment method used by shipbuilding companies has the highest cost, reaching 1,005,600 US dollars, while the joint replenishment method has the lowest cost, which is 532,480 US dollars, which is a decrease of 473,120 US dollars, a decrease of $47 \%$. In the total cost calculated by the monthly replenishment method adopted by the shipbuilding company, the inventory storage fee reached 518,400 US dollars, indicating that the inventory storage cost took up a large amount of the shipbuilding company's working capital, which should cause the shipbuilding company to attach great importance to it.

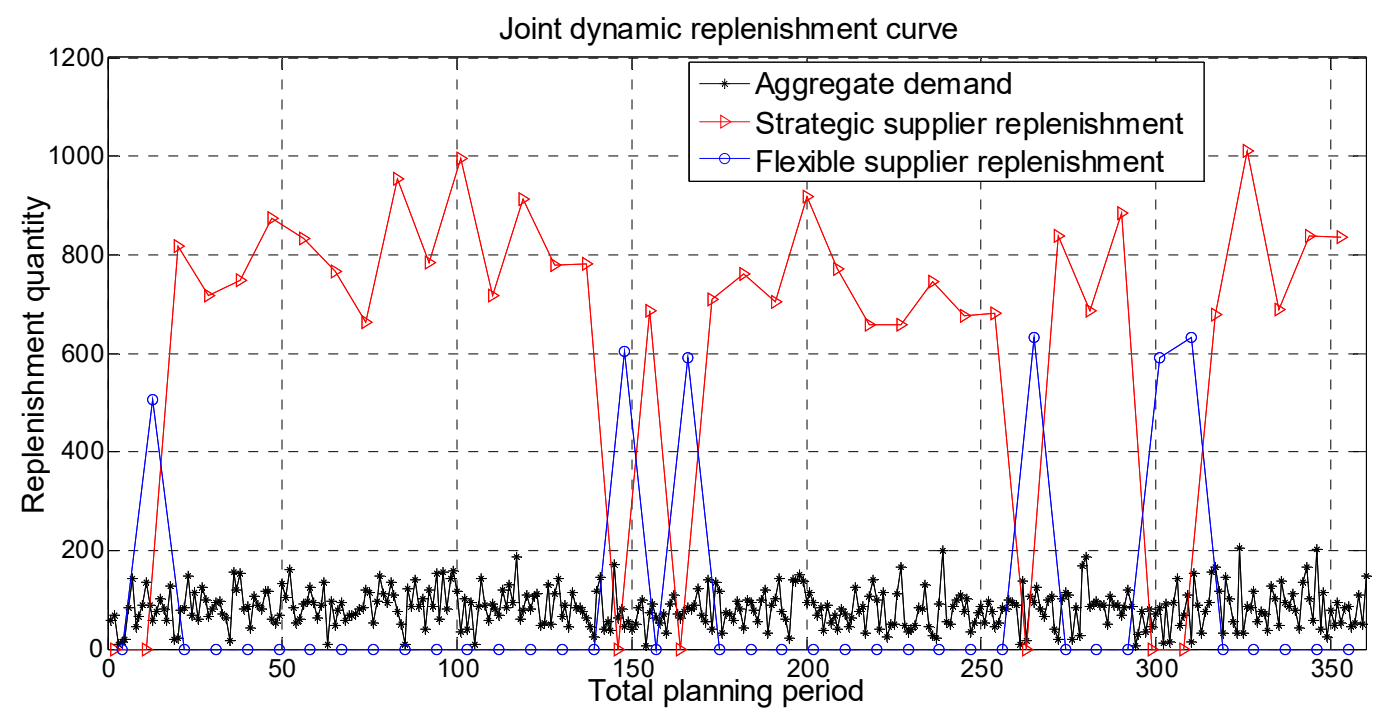

Figure 3. Comparison of different replenishment methods from strategic suppliers and flexible suppliers.

Table 1. Dynamic replenishment costs of different methods (unit: USD).

\begin{tabular}{ccc}
\hline Replenishment Method & Total Cost & Total Cost Increase \\
\hline Joint replenishment method & 523,650 & - \\
\hline Replenishment methods from strategic suppliers & 535,050 & 11,400 \\
\hline Replenishment methods from general suppliers & 548,490 & 24,840 \\
\hline $\begin{array}{c}\text { Shipbuilding companies adopt } \\
\text { replenishment methods }\end{array}$ & $1,005,600$ & 473,120 \\
\hline
\end{tabular}

\subsection{Sensitivity Analysis}

To analyze the influence of model parameters on the collaborative replenishment strategy, the sensitivity analysis of the service level $S L$ and $I W_{1}$ is carried out below. Table 2 shows the sensitivity analysis of replenishment costs under different initial inventory values. It can be seen from Table 2 that when the initial inventory of paint increases from 160 to $U$, the total cost of joint replenishment decreases successively, indicating that it is reasonable to take $U$ for the initial inventory in this model. Table 3 shows the correspondence between different service levels and critical values. The critical value is also called the safety factor, which can be obtained by checking the standard normal distribution table. It can be seen 
from Table 4 that as the service level $S L$ decreases from $96 \%$ to $85 \%$, the total cost of paint for shipbuilding companies gradually decreases, indicating that the higher the service level, the higher safety inventory is required; the service level $S L$ decreases from $85 \%$. If it drops to $50 \%$, the out-of-stock cost will increase significantly, and the total cost will increase. The general service level cannot be lower than $85 \%$, generally $88-99 \%$. Shipbuilding companies are custom-made and are more sensitive to out-of-stocks, so this article uses $95 \%$.

Table 2. Sensitivity analysis of dynamic collaborative replenishment costs under different initial values (unit: USD).

\begin{tabular}{ccccccccc}
\hline Initial Value & $\mathbf{1 6 0}$ & $\mathbf{4 0 0}$ & $\mathbf{5 0 0}$ & $\mathbf{6 0 0}$ & $\mathbf{8 0 0}$ & $\mathbf{9 0 0}$ & $\mathbf{1 0 0 0}$ & $\mathbf{U}$ \\
\hline Co-replenishment costs & 533,480 & 531,220 & 530,440 & 528,710 & 526,980 & 525,900 & 524,820 & 523,650 \\
\hline
\end{tabular}

Table 3. Correspondence between service level and critical value.

\begin{tabular}{ccccccccc}
\hline Service Level (\%) & $\mathbf{9 8}$ & $\mathbf{9 5}$ & $\mathbf{9 2}$ & $\mathbf{9 0}$ & $\mathbf{8 5}$ & $\mathbf{8 0}$ & $\mathbf{6 0}$ & $\mathbf{5 0}$ \\
\hline Critical value & 2.06 & 1.65 & 1.41 & 1.29 & 1.03 & 0.85 & 0.26 & 0 \\
\hline
\end{tabular}

Table 4. Sensitivity analysis of dynamic replenishment costs under different service levels (unit: USD).

\begin{tabular}{cccc}
\hline Service Level (\%) & $\begin{array}{c}\text { The Total Cost of } \\
\text { Collaborative } \\
\text { Replenishment }\end{array}$ & $\begin{array}{c}\text { Replenishment from } \\
\text { Strategic Suppliers }\end{array}$ & $\begin{array}{c}\text { Replenishment from } \\
\text { Flexible Suppliers }\end{array}$ \\
\hline 98 & 528,620 & $540,530(11,910)$ & $550,600(21,980)$ \\
\hline 95 & 523,650 & $535,050(11,400)$ & $548,490(24,840)$ \\
\hline 92 & 514,970 & $526,060(11,090)$ & $542,000(27,030)$ \\
\hline 90 & 510,630 & $521,580(10,950)$ & $538,890(28,260)$ \\
\hline 85 & 501,700 & $512,330(10,630)$ & $523,100(21,400)$ \\
\hline 80 & 512,590 & $523,910(11,320)$ & $534,240(21,650)$ \\
\hline 60 & 524,520 & $537,370(12,850)$ & $547,100(22,580)$ \\
\hline 50 & 529,070 & $542,050(12,980)$ & $553,650(24,580)$ \\
\hline
\end{tabular}

Note: The costs in parentheses are increased relative to the total cost of joint replenishment.

According to the results from Tables 2-4 and the above analysis, the following conclusions can be drawn: (1) under uncertain conditions, the total cost of collaborative replenishment is less than the total cost of replenishment only from strategic suppliers, while the total cost of replenishment only from strategic suppliers is less than the total cost of replenishment only from flexible suppliers; (2) the service-level parameter represents the minimum requirement of shipbuilding enterprises for the demand satisfaction rate of certain raw materials or parts. When the service-level parameter is relatively high, the total cost is also high, which is because the higher safety inventory requires higher costs to manage so that the corresponding inventory construction cost investment is large, to resist the risk of shortage caused by demand uncertainty. However, when the service level is low, although the inventory management cost is low, the shortage cost increases extremely significantly, resulting in a rapid increase in the total cost.

\section{Discussion}

The competition in the global shipbuilding industry is becoming increasingly fierce. If shipbuilding enterprises want to remain invincible, they must maintain their core competitiveness and quickly deal with uncertainty. Shipbuilding enterprises need to establish effective integrated supply chain management in which inventory management is one of 
the key activities. The integrated supply chain management adopted by shipbuilding enterprises can effectively reduce the shipbuilding costs, shorten the shipbuilding cycle, improve the enterprise management level and ship quality, enhance the market competitiveness of shipbuilding enterprises, and improve the economic benefits of shipbuilding enterprises. This paper analyzes the inventory control decision-making activities of a shipbuilding enterprise by using the coordination theory and the idea of supply chain integration, selects the paint materials in the inventory as the optimization object to reduce the inventory, and improves the inventory management level significantly. This study has the following management implications:

(1) The dynamic collaborative replenishment optimization model of shipbuilding enterprise inventory control proposed in this paper can help shipbuilding enterprise decision-makers minimize the total inventory cost. Making full use of the respective advantages of strategic suppliers and flexible suppliers, the two supplier ordering strategies play a game with each other in the shipbuilding supply chain system, and there is a relationship of both competition and cooperation. The advantage of strategic suppliers is to pursue flat production in order to reduce production costs; the primary consideration of flexible suppliers is to quickly respond to the uncertain demand of the market. Analyzing the inventory control principle of shipbuilding enterprises with the idea of coordination theory and supply chain integration can help to make full use of the advantages of strategic suppliers and flexible suppliers, avoid their disadvantages, and better reduce the total inventory cost.

(2) Since January 2020, novel coronavirus pneumonia has been spreading worldwide. Although the global scientific and medical circles are making every effort to fight the pandemic, it is difficult to predict how the pandemic will develop in the future, and its impact on social development has appeared in many aspects. Infectious diseases such as novel coronavirus pneumonia are constantly emerging. They spread widely, spread rapidly, and cause great social harm. Novel coronavirus pneumonia is a new type of public health emergency. It needs comprehensive emergency management and needs a coordinated response from different countries and regions. It is necessary to strengthen international macroeconomic policy coordination, maintain a stable and smooth supply chain of the global industrial chain, and jointly cope with the new crown pneumonia epidemic. Novel coronavirus pneumonia and other infectious diseases are of great importance in the process of shipbuilding. We need to have strong, unified organization and implementation in the aspects of flow control, material distribution, and social security to maximize the efficiency of resource allocation in shipbuilding. The inventory management of shipbuilding enterprises is an important link affecting the allocation efficiency of shipbuilding resources. It is an integral part of the cost of the shipbuilding supply chain. It has an important impact on the response and logistics time of the whole shipbuilding supply chain.

(3) Under uncertain conditions, the total cost of inventory control of shipbuilding enterprises will gradually increase with the increase in decision-makers' requirements for service level and reliability level. Therefore, in the actual inventory control decisionmaking of shipbuilding enterprises, decision-makers should appropriately select the service-level positioning of inventory control and fully consider their shortage cost ability, that is, risk tolerance, so as to achieve the ideal decision-making goal within the reasonable total cost budget.

\section{Conclusions}

Due to the lack of sufficient information on the inventory control of shipbuilding companies coupled with the complicated and variable production process, the uncertainty of the needs of each workshop has brought a negative impact on shipbuilding companies and has also put forward new requirements for shipbuilding supply chain management. Quickly responding to changes in demand while maintaining low operating costs can be achieved through the dynamic collaborative replenishment of the two types of suppliers 
in the shipbuilding supply chain system to improve scientific and practical inventory management.

(1) Analyze the principle of the inventory control of shipbuilding enterprises with synergy theory and the idea of supply chain integration, and then establish a dynamic collaborative replenishment model for inventory control. To solve the dual-objective replenishment model that maximizes the service level and minimizes the total cost, the bounded objective method is used to solve the problem. The main goal is to minimize the total cost, and the service level target is limited to a satisfactory range to obtain the total cost of different service levels. The results show that, firstly, the dynamic collaborative replenishment model of inventory control in shipbuilding enterprises can make full use of the advantages of two types of suppliers, which can not only respond to demand changes quickly, but also maintain low operation costs; secondly, to improve the service level and avoid the probability of shortage, we must increase the safety stock. However, excessive reserve inventory is very uneconomic, and corresponding cost management needs to be increased. Therefore, shipbuilding enterprises should comprehensively consider the supply and demand, transportation conditions, and other factors to determine a safety inventory that can not only ensure the production needs, but also the lowest inventory.

(2) The scope of research on the inventory control of shipbuilding enterprises under uncertain conditions is relatively wide, relatively complex, and involves more subject knowledge. The next step can be pursued around the following aspects. One is to study the multi-product, multilevel supply chain. This article restricts the research object to a secondary supply chain consisting of a shipbuilding company, a strategic manufacturer, and a flexible supplier and assumes that there is only one simplified form of product, but there will be multiple products in the actual supply chain network and multilevel supply chain situation. The second is to use an appropriate probability distribution to fit the random demand of different products. The dynamic collaborative replenishment model of shipbuilding enterprise inventory control proposed in this paper can provide an important theoretical reference for inventory control decision-making departments of shipbuilding enterprises.

Author Contributions: Conceptualization, Z.X. and M.H.N.; methodology, Z.X.; software, Z.X and M.H.N.; validation, W.G., Z.X. and M.H.N.; formal analysis, Z.X.; investigation, Z.X.; resources, M.H.N.; data curation, Z.X and W.G.; writing—original draft preparation, Z.X. and M.H.N.; writingreview and editing, M.H.N.; visualization, Z.X. and W.G.; supervision, J.Y.; project administration, J.Y.; funding acquisition, Z.X. and J.Y. All authors have read and agreed to the published version of manuscript.

Funding: This research was supported by the High-tech Ship Research Project of the Ministry of Industry and Technology of China (MC-202009-Z03).

Institutional Review Board Statement: Not applicable.

Informed Consent Statement: Not applicable.

Data Availability Statement: The data used to support the findings of this study are included in Tables 1-4.

Conflicts of Interest: The authors declare no conflict of interest.

\section{References}

1. Xuejie, N. IoT study on the total risk management and cluster-coordinated development based on synergy theory. Cogn. Syst. Res. 2018, 52, 809-815. [CrossRef]

2. Deb, M.; Kaur, P.; Sarma, K.K. Fuzzy Approach to Decision Support System Design for Inventory Control and Management. J. Intell. Syst. 2019, 28, 549-557. [CrossRef]

3. Yu, W.; Hou, G.; Xia, P. Supply Chain Joint Inventory Management and Cost Optimization Based on Ant Colony Algorithm and Fuzzy Model. Teh. Vjesn. 2019, 26, 1729-1737.

4. Maiti, A.K. Multi-item fuzzy inventory model for deteriorating items in multi-outlet under single management. J. Manag. Anal. 2020, 7, 44-68. [CrossRef] 
5. Sadeghi, J.; Niaki, S.T.A. Two parameter tuned multi-objective evolutionary algorithms for a bi-objective vendor managed inventory model with trapezoidal fuzzy demand. Appl. Soft Comput. J. 2015, 30, 567-576. [CrossRef]

6. Jaggi, C.K.; Pareek, S.; Goel, S.K.; Nidhi. An inventory model for deteriorating items with ramp type demand under fuzzy environment. Int. J. Logist. Syst. Manag. 2015, 22, 174-179. [CrossRef]

7. Mor, R.S.; Kumar, D.; Yadav, S.; Jaiswal, S.K. Achieving cost efficiency through increased inventory leanness: Evidence from manufacturing industry. Prod. Eng. Arch. 2021, 27, 412-433. [CrossRef]

8. Borle, P.S.; Tapare, V.S.; Pranita, A. Drug Inventory Control and Management: A Case Study in Rural Health Training Center (RHTC), Tasgaon. Indian J. Public Health Res. Dev. 2014, 5, 174-177. [CrossRef]

9. Budynek, M.; Celińska, E.; Dybikowska, A.; Kozak, M.; Ratajczak, J.; Urban, J.; Materne, K. Strategies of Production Control as Tools of Efficient Management of Production Enterprises. Manag. Syst. Prod. Eng. 2016, 21, 20-24. [CrossRef]

10. Gerard, P. Cachon, Marshall Fisher. Supply Chain Inventory Management and the Value of Shared Information. Manag. Sci. 2000, $46,1032-1048$.

11. Lee, J.E. Study on Reducing Logistics Costs and Inventory Control System according to facilities integration in the Closed-Loop Supply Chain Environment. J. Korea Ind. Inf. Syst. Res. 2014, 19, 81-90.

12. Kelly, R. Production and Inventory Control: Roadmaps and Strategies for Business Improvement; Taylor and Francis: Abingdon, UK, 2021.

13. Wang, C.N.; Dang, T.T.; Nguyen, N.A.T. A computational model for determining levels of factors in inventory management using response surface methodology. Mathematics 2020, 8, 1210. [CrossRef]

14. Yingying, Z.; Yi, C.; Le, M. Research on Multi-Echelon Inventory Optimization for Fresh Products in Supply Chains. Sustainability 2021, 13, 6309. [CrossRef]

15. Sutrisno; Widowati; Tjahjana, R.H. Piecewise objective optimisation model for inventory control integrated with supplier selection considering discount. Int. J. Logist. Syst. Manag. 2020, 38, 65-78. [CrossRef]

16. Stockbridge, R.B. The application of Poisson distribution statistics in ion channel reconstitution to determine oligomeric architecture. Methods Enzymol. 2021, 652, 321-340. [CrossRef] [PubMed]

17. Virendra, K. On the generalized fractional Laplace transform. Moroc. J. Pure Appl. Anal. 2021, 7, 448-460.

18. Hulse, T.A.; Kuan, C.I.; Lowry-Duda, D.; Walker, A. The laplace transform of the second moment in the gauss circle problem. Algebr. Number Theory 2021, 15, 1-30. [CrossRef]

19. Ziquan, X.; Jiaqi, Y.; Hamza Naseem, M.; Zuquan, X. Solving the Multiobjective Transportation Decision-Making Problem Based on Improved S-Type Membership Function. J. Math. 2021, 2021, 4169352. [CrossRef]

20. Xiang, Z.; Yang, J.; Li, H.; Liang, X. A solution to resource allocation problem based on discrete grey wolf optimizer. Huazhong Keji Daxue Xuebao (Ziran Kexue Ban)/J. Huazhong Univ. Sci. Technol. 2021, 49, 81-85. [CrossRef] 